\title{
Managing Uncertainties in Digital Democracy \\ Experiments: A Case Study of the Management of the Stem Van West Experiment in Amsterdam-West, the Netherlands
}

\author{
Dr. Vidar Stevens (corresponding author) \\ Mulier Instituut \\ Herculesplein 269, 3584AA, Utrecht, The Netherlands \\ E-mail: v.stevens@mulierinstituut.nl
}

Received: Jan. 17, 2020 Accepted: Feb. 26, 2020 Online published: Mar. 2, 2020

doi:10.5296/jpag.v10i1.16252ＵRL: https://doi.org/10.5296/jpag.v10i1.16252

\begin{abstract}
Can we use digital tools to increase and deepen citizen participation in open and democratic policy-making processes? That is the main question this article aims to address. Today, there is a global effort to foster democracies through online digital tools. However, for many governmental officials and scholars it is still a challenge to decipher how online digital tools technically function and operate, what effects such tools have on the users of the platforms, and how it impacts the practices of governmental organizations and politics. In our view, practices of digital democracy deserve more governmental attention. Anno 2018, we already do our banking, tax-payment, and data sharing online. Nonetheless, our democracy remains decidedly analogue; the activity of casting a vote requires citizens to go the local polling booth, queue up, and tick a box on a paper voting slip. As such, the aim of this article is to shed more light on this new way of thinking about democracy in the digital era. Furthermore, we want to show the readership how in a time where there is growing disillusionment with the political institutions of advanced Western democracies, online tools provide new ways of involving citizens in political decision-making. Therefore, in this article we explore the possibilities of digital tools regarding citizen participation and democracy, and particularly, focus on how to manage these political experiments.
\end{abstract}

Keywords: digital democracy, management, uncertainties, governance, citizen participation 


\section{Introduction}

How can digital democracy processes be managed to deepen citizen participation in policy-making processes? That is the main question this article aims to address. Today, there is a global effort to foster democracies through online digital tools. However, for many governmental officials and scholars it is still a challenge to decipher how online digital tools technically function and operate, what effects such tools have on the users of the platforms, and how it impacts the practices of governmental organizations and politics. Therefore, in this article we explore the possibilities of digital tools regarding citizen participation and democracy. Specifically, we examine a Dutch case, called 'De Stem van West' (translated 'the Voice of West', hereafter referred to as $\mathrm{SvW}$ ). This digital tool facilitates the policy-making process of the neighborhood council of Amsterdam-West. Citizens of the neighborhood can vote on plans, voice their concerns, and upload ideas and proposals themselves. The tool was recognized by Eurocities as one of Europe's most innovative digital democracy experiment. The SvW digital tool can thus be regarded as an exemplary case of how to organize a digital democracy process. Hence, by examining the case in Amsterdam-West, we aim to gain a better understanding of the potential and use of digital democracy tools.

We decide to look from an applied e-democracy perspective to the case. An applied e-democracy perspective can best be understood as a focus on the managerial challenges surrounding the actual development and implementation of these digital tools (Mulder \& Hartog, 2013: 22). In line, with Mulder and Hartog (2013), we claim that current digital democracy research is largely disconnected from application. Most digital democracy scholar have focused on democratic innovations, like digital democracy tools, from a normative democracy perspective or a deliberative democracy theory (e.g. Smith, 2008). Nevertheless, limited studies have scrutinized general notions and assumptions on the design of e-democracy solutions (but see Karlsson, 2010). In addition, there is a high number of disappointing practical results in the field of digital participation and e-democracy (see, for instance, the results of the studies of Dunne, 2008; Milner, 2002; Ostling, 2010; Peňa-Lopez, 2011). To this end, by particularly focusing on the distinct uncertainties managers face in digital democracy processes, we believe that better digital democracy systems can be designed which link properly to the political-administrative contexts in which they are incorporated.

Based on an analysis of relevant (policy) documents, thirteen interviews, a quantitative coding analysis of all online discussions and two video observations, we discuss in subsequent order: the theoretical section, the case, the method section, the empirics, and the final reflections that follow from the article. Overall, we show, in this article, that when working with digital democracy tools, policymakers face three types of uncertainties: product-, substantive-, and strategic uncertainties. Moreover, from the Amsterdam-West case, specific managerial strategies can be distilled that help to overcome, or at least deal, with these uncertainties. Yet, as a start, we begin the article by arguing that the field of digital democracy is in need for a more applied digital democracy perspective. 


\section{A Call for Applied E-Democracy Theory}

Following the general development of ICT, we have witnessed a growing urgency for digital facilitation of democratic processes (Mulder \& Hartog, 2013). West (2005: 102), for example, argues that with new ICT-developments it becomes easier for government officials to attract new citizenry to decision-making processes. In similar vein, Chambers (2003: 316), inter alia, believes that the 'wisdom of the crowd' can be further enacted by e-participation, ensuring better informed policies and (eventually) greater support for government's actions. Nevertheless, despite the promise of digital forms of democracy to reverse political disengagement (Dunne, 2008), there is a high number of disappointing practical results in the field of e-participation and e-democracy (e.g. Dunne, 2008; Milner, 2002; Ostling, 2010; Peňa-Lopez, 2011). In fact, Ostling (2010) argues, by using Gartner's' hype cycle, that e-democracy can currently best be positioned between the 'peak of inflated expectations' and 'trough of disillusionment'. This means that, despite the promise e-democracy practices hold, current e-democracy system designs barely link properly to the political-administrative context in which they are implemented. Hence, Mulder and Hartog (2013) have argued more attention should be devoted to an 'applied e-democracy perspective'.

An applied e-democracy perspective can best be understood as a focus on supporting the existing democratic processes with digital tools (as opposed to new developments like social media) and on the challenges surrounding the actual development and implementation of these digital tools (Mulder \& Hartog, 2013: 22). The authors claim that current e-democracy research is disconnected from application. So far, most studies have focused on democratic innovations, like digital democracy tools, from a normative democracy perspective or a deliberative democracy theory (e.g. Smith, 2008). Nevertheless, limited studies have scrutinized general notions and assumptions on the design, implementation and execution of e-democracy solutions, and its management (but see Karlsson, 2010). In line with Muller (2011), Mulder and Hartog propose a more architectural way of thinking when discussing and examining practices of e-democracy and participation. They argue, "an architectural perspective is a method supporting 'the e-democracy' architect in the process to go from a vague notion of the problem and potential digital solutions to a well-articulated and well-structured architecture description" (Mulder and Hartog, 2013: 26). We interpret this architectural perspective as a call for more research on the specific design-related issues, and managerial challenges, that surround the development, incorporation, and execution of digital participation tools.

Mulder and Hartog (2013) do not really propose a conceptual framework for their 'applied democracy perspective'. Their paper is mostly a statement for focus on the practical challenges with digital participation solutions. Inspired by network governance theorists (like Koppenjan \& Klijn, 2004), we, however, expect three types of uncertainties to be present, and need to be managed, when developing and adopting digital democracy tools: product uncertainty, substantive uncertainty, and strategic uncertainty.

\subsection{Product Uncertainty}

Product uncertainty refers to the complexity for developing a digital participation tool, as a 
new decision-making channel, next to existing democratic arrangements and governmental practices. One of the virtues of technology is that it long has been thought to be an ideal way of restoring of direct democracy to large-scale societies. In an era where it is physically impossible to bring together all citizens under one 'town-hall roof' and have them participate in communal decisions, ICT technology offers the prospect of electronic communication and participation in community decision-making. In this way, it overcomes the problem of geographical 'distance' between people to deliberate about public matters. Nevertheless, as West (2005: 103) points out, while the technology capacity to facilitate greater responsiveness is available, many (local) governments have not taken full advantage of the new possibilities. In fact, there remain barriers to usage, like, how new digital participation tools fit with a disparity of user preferences of citizens, existing institutional regimes, and routine administrative behaviors during ordinary democratic processes. Product uncertainty, as such, highlights the necessity for developing a digital participation tool that fits and supports, or at least considers, existing organizational regimes and democratic practices.

\subsection{Substantive Uncertainty}

Substantive uncertainty springs from the different perceptions individuals (can) have about the nature of problems, their causes, and possible solutions (Klijn \& Koppenjan, 2016: 12). ICT technologies, like Internet applications, facilitates communications between citizens by adding an interactive component that allows people to send and receive messages. The development of a digital participation tool, as such, has the potential to democratize mass communications. Differences in views and opinions, however, do not make it easy for participants in digital democracy processes to reach consensus on a possible policy solution. In fact, coordinators of digital participation processes must consider the erratic and unpredictable 'debating nature' of interactions between participants. With erratic debating nature, we mean, that the interactions or discussions in the debates on the digital platform will not have a fixed or regular course; the discussions can wander. Hereby, it is most important that the effect of the loudest voices on the digital platform becoming dominant is mitigated, and that minority viewpoints also get equal weight and attention on the discussion's digital interface (West, 2005). Hence, in the design of, and during the discussions on, a digital participation tool, coordinators must manage discussions in such a way that democratic conversation between citizens and government is fostered.

\subsection{Strategic Uncertainty}

Strategic uncertainty relates to the choices involved actors can make regarding implementing output following from discussions on a digital tool. A digital democracy process is not mere an online discussion. After an online discussion is finished, a citizen's proposal must be implemented and executed. Different actors, like politicians, civil servants, and the promotors of the citizen's proposal, will be involved in the implementation- and execution process. To some extent, the way in which an outcome of a digital participation discussion is implemented and executed touches upon the aspect of responsiveness of the government to requests of 'ordinary' citizens. In democratic political systems democratic responsiveness is a key requirement (West, 2005: 111). The expectation is that government leaders respond to 
citizen concerns and answer basic kinds of inquiries. Nevertheless, because actors (like politicians, civil servants, and promotors of citizen's proposal) ground their strategies and behaviors in unique perceptions, which other actors sometimes do not acknowledge or are unaware of, a large variety of actor strategies or inefficient interactions can emerge in the implementation and execution of digital participation outcomes (Klijn \& Koppenjan, 2016: 13). In the worst case, the inefficient interactions or strategic actor behaviors cause that, although most of the participants on the digital participation platform supported the citizen's idea, the proposal is eventually not implemented or executed. To this end, strategic uncertainty considers how unexpected strategic turns, interactions, and various actor strategies will influence the eventually implementation of a citizen's proposal that was agreed upon on the digital participation interface.

We do not assume that all three uncertainties will be equally present in all digital democracy projects. Also, the three types of uncertainties will in many cases be interrelated. As such, we consider a contingency approach, in this article, to understand practical obstacles to the design, implementation and execution of digital participation projects. This means that we expect that different governance- and organizational dynamics place distinct kinds of demands and sorts of uncertainties on designers and coordinators of digital democracy processes. In this article, the focus will be on whether in the empirical SvW case the three types of uncertainties can be identified, in what form these types of uncertainties emerged, and how managers responded to the uncertainties. In this way, this article empirically drills down into the 'management variable', which allows to explore why, despite various types of uncertainties in the empirical case, the digital participation project in Amsterdam-West was successful. Before we move on to the methods section, we introduce Stem van West case.

\section{Case: Stem Van West, Amsterdam, the Netherlands}

Since 2014, when the local elections were held, the governing parties of the neighborhood council were looking for new (online) ways to reconnect with civil society organizations in the neighborhood and attract new citizens to the decision-making processes (respondent 1). In addition, within neighborhood administration, a digitalization team was set up to look for new ways to incorporate ICT tools and practices in the bureaucratic machinery (respondent 7). Hence, in the neighborhood of Amsterdam-West there was a lot of momentum to experiment with digital tools. During the neighborhood council meeting of 18 December 2015, the neighborhood council members decided to effectively start their own digital democracy test case. Many neighborhood council members got inspired by the success stories of the democratic experimentations of the open-source digital democracy tool YourPriorities in Barcelona, Madrid, Reykjavik and Helsinki. These experimentations were a part of the European D-CENT project (respondent 11). As such, after reflecting on the case study reports of these international experiments, the neighborhood council decided to make three years of funding available for programmers to develop a YourPriorities app for the neighborhood of Amsterdam-West, called the Stem van West (SvW). The SvW application was officially launched in January 2017. 


\section{Macrothink}

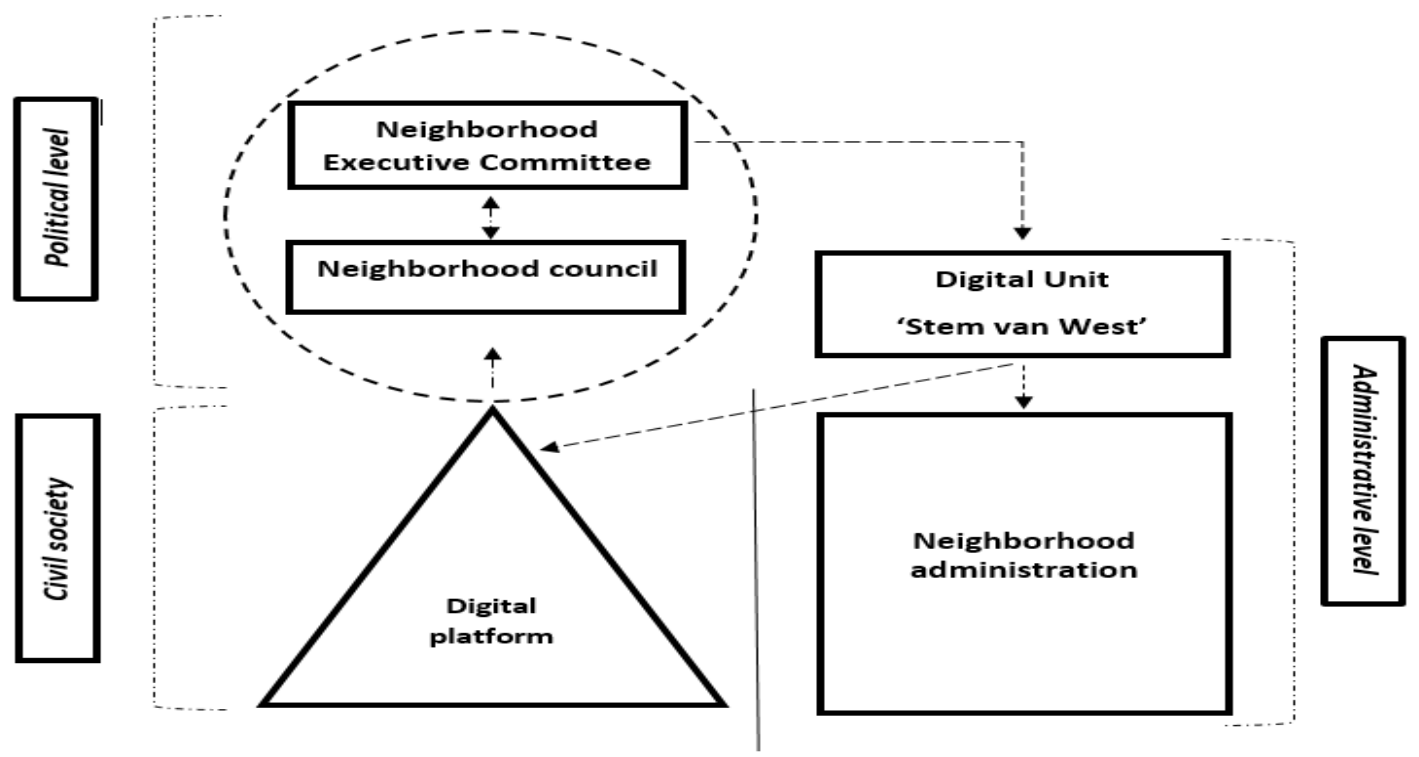

Figure 1. Governance infrastructure of the $\mathrm{SvW}$ project

In the $\mathrm{SvW}$ direct democracy program there are clear role demarcations between involved (governmental) actors (see figure 1). Citizens can add ideas onto the digital platform. Neighborhood council members (i.e. politicians) or civil servants who work for the neighborhood administration are thus not allowed to contribute in any substantive way to the online discussions. Only the Digital Unit of the neighborhood administration, which consists of four freelance expert people, can execute maintenance works on the digital platform. Promotors of the ideas provide, on the digital platform's interface, points in support of their ideas. Other participants can comment on these ideas and arguments. This informs and sparks initial debate. The ideas and arguments that have been introduced are, subsequently, up-voted and down-voted to show what the most popular ideas and best arguments for and against the proposals are. If an idea on the platform's interface surpasses the threshold of 100 positive votes within three months, the proposal will be put on the monthly agenda of the neighborhood council. In the neighborhood council meeting, the promotor of the idea will have 30 minutes to reflect on the online discussions, the arguments in favor of and against the idea, and the possible costs of the project. After half an hour, the neighborhood council will deliberate on the idea without the involvement of the promotor of the idea.

When, after deliberation, a majority of the neighborhood council members agree with the promotor's idea, the project will be sent through to the neighborhood administration to see whether it can be incorporated in existing policy plans, or whether the proposal collides with other bureaucratic activities. If the latter is not the case, the citizen's proposal will be executed by civil servants, and, under the supervision of a neighborhood alderman (who is a part of the neighborhood executive committee), in close cooperation with the promotor of the idea. As such, ideally, the SvW digital tool enables better decision-making by crowdsourcing policy design. In the next section, we elaborate on the methods we used to examine if the neighborhood council and -administration encountered product-, substantive-, and strategic 
uncertainties, and if so, how they managerially dealt with these uncertainties.

\section{Methods}

For this study, a single case-study approach was used. We acknowledge the inherent limitations of using single case studies for extrapolating findings, as was described by George and Bennett (2005). Yet, we also agree with Flyvbjerg (2011: 305) when he argues that a case study can further scientific development by the force of example. To this end, we do not pretend that the observations in the thick description are fully generalizable or highly theoretical. However, we are convinced that the article's reflections are helpful in substantiating the development of an applied (management) theory on the impact of digital tools on citizen participation and democracy.

For the data collection, we drew on a detailed process mapping based on an analysis of documents and a series of interviews (Koppenjan and Klijn, 2004: 136-137). The document analysis included policy documents, meeting minutes, position papers, annual reports, evaluations and implementation plans of the stakeholders involved. The relevance of the documents was determined by making a selection based on whether the information in the documents said something new or extra about the context in which the digital participation initiative was launched, the peculiarities of the digital participation process, organizational characteristics of the tool, individual-level aspects of stakeholders in the democratic process, and the output of the SvW initiative. The document analysis was complete once we reached data saturation.

Subsequently, the thirteen interviews helped to gain more insight into the opinions, objections, ideas, attitudes, and experiences of the stakeholders regarding the use and value of the digital tool to foster citizen participation in Amsterdam-West. The interviews were semi-structured, and the questions concentrated on the dimensions of the uncertainty's framework, presented in the theoretical section. The interviews typically lasted for 1.5 hours. Each interview was recorded and transcribed. We promised our respondents anonymity. Therefore, we numbered the interviews and used the phrase 'respondent (number)' to report quotes from the interviews in this article. We triangulated the interview data by comparing the interview responses to each other and to the document analysis findings. If we ran into inconsistencies, we followed up with respondents to ask for clarification.

Furthermore, we conducted two one-hour video observations in the neighbourhood council, to get a better gist of the functioning of the neighbourhood council of Amsterdam-West and to understand how the council members operated with the new channel of decision-making next to the ordinary political process. The video observations also allowed us to gain more insights in how citizens promoted their idea, if put on the political agenda, to the neighbourhood council members and to hear from them how they gained local support for their proposals. The video observations took place on December 18, 2015 and July 4, 2017. Lastly, we coded and quantified all digital platform discussions, proposals and arguments to evaluate what type of issues or proposal had most societal impact (in terms of amount of votes in favour and against the proposal and positive discussions) and political impact (in terms of 'being' discussed on the neighbourhood council meetings). An overview of the last exercise is 
presented in table 1 . These four methods combined allowed us to make an assessment of what kind of uncertainties managers of the SvW project faced and how they coped with these uncertainties in the Amsterdam-West case. The results of the case study analysis are presented in the next section.

\section{Results}

In the next sections, we discuss the uncertainties surrounding the SvW project. The 'manager' that is central in our analysis differs per type of uncertainty. In the case of product uncertainty, the developers were mostly managing the product development process. With regard to substantive uncertainty issues, neighbourhood politicians were assigned with the task to neutrally foster debate on the open-source digital participation tool. During the implementation and execution of citizen's ideas, the responsible alderman and selected civil servants were tasked with nurturing strategic behaviours of involved actors. For each type of uncertainty, the following sections describe the management aims (i.e. what uncertainties did the manager have to tame), solutions (i.e. what management strategies were used to tame the uncertainties), and effect (i.e. what impact did the management strategy have). In this way, we zoom in on the management of uncertainties in the digital democracy project of Amsterdam-West.

\subsection{Product Uncertainty}

\subsubsection{Management Aims}

The formal goals of the SvW initiative were threefold (respondent 1). The first goal was to develop a digital tool which would bring people together to debate and prioritize innovative ideas to improve their local communities. The second goal was more citizen-oriented, as the neighborhood council aimed at helping citizens get their voices heard and to encourage citizen participation in governance. The third goal of the digital democracy initiative was to develop, with the help of open-source tools, a new digital infrastructure that would allow the neighborhood administration to expand and renew their participatory governance toolbox. According to respondent 3, the formal goals demanded the developers to come up with a tool which would align with the user expectations of citizens from the Amsterdam-West neighborhood, and, at the same time, consider the existing democratic- and governance practices of the neighborhood administration.

Moreover, specific developers' attention had to be devoted to the legal framework of laws and formal documents to which the digital tool had to adhere. One of the documents which was a part of this legal framework is the Open Source Definition Framework (OSDF). The OSDF, inter alia, demands that a tool's source code is freely accessible (respondent 7). The developers further had to consider the privacy standards which follow, inter alia, from the Dutch Personal Data Protection Act. The law text ensures that personal data of participants of the $\mathrm{SvW}$ tool is only stored for a limited amount of time for specific purposes (e.g. registering the amount of 'real voters' for a proposal on the tool's interface). At all times, participants can command the proprietor of the tool to withdraw their personal data (respondent 7).

As such, during the development of the SvW tool the developer's team thus focused on 
various key aspects to develop the most applicable tool for the Amsterdam-West politicaland administrative context, to mention: the different user groups and their preferences, the democratic- and governance dynamics, open-source code development, and aspects of privacy and personal data. Three specific strategies were introduced to deal with these uncertainties and demands: (1) user-centered design research, (2) minimum viable product development and modular programming, and (3) collaborative instrument evaluation team.

\subsubsection{Solution 1: User-Centered Research Design}

The user-centered design research phase was an interactive design processes in which the developers of the $\mathrm{SvW}$ tool focused on the potential users of the tool, their online and offline behaviors, their needs to interact with the neighborhood council, and the ways in which they would normally enter webpages (e.g. direct through the separate webpage or 'through the backdoor', like: a Facebook link). The phase started with mapping the different users of the tool, these were: (1) people who wanted to upload an idea, (2) people who only wanted to comment on ideas, (3) people who only wanted to vote on ideas, (4) people who just wanted to know what was going on in their neighborhood, and (5) civil servants and neighborhood council members who would eventually have to execute the new policy ideas. For each of type of user group, various citizens of the neighborhood were invited to join a discussion with the developers about their user preferences, because, as respondent 8 argues, these different user groups demanded different user requirements. Some people only wanted to have a quick peek on the tool's platform, whereas other participants wanted more elaborate user functions, like uploading photos. In the discussion meetings, two types of discussion methods were used: investigative (e.g. surveys and interviews) and generative (i.e. brainstorming sessions) methods. Ultimately, this phase enabled the development of tailor-made products, which align with the specific user needs for citizens in Amsterdam-West, for digital participation use. 5.1.3 Solution 2: Minimum Viable Product Development and Proto Testing

Following the outcomes of the user-centered design research, a minimum viable product was developed. A minimum viable product can be regarded as the most simplistic version of the digital tool (respondent 7). It has just enough functions to be launched and to provide feedback for future product development. Gathering insights from a minimum viable product is, according to respondent 8, less expensive than developing a full-fledged product with more digital features, which increases costs and risks if the full-fledged digital tool fails, for example, due to incorrect user assumptions. The minimum viable product was, subsequently, proto-tested in a small courtyard in the Amsterdam-West area, called the Spaarndammerbuurt (respondent 1). On the interface of the minimum viable product, citizens could upload and comment on ideas for repainting a bicycle tunnel. There was an enormous response, as the neighborhood council received 49 different art impressions (respondent 6). Yet, more importantly, the developers of the SvW tool retrieved new user's information, updates on bugs in the tool, and suggestions for changes in the voting procedures on the platform (respondent 8). This information was eventually used to update the minimum viable product and change it to the current version of the tool which can be accessed open source on GitHub. 


\subsubsection{Solution 3: Collaborative Team}

To create enough discretionary space for the developer's team to fine-tune a tool which could one-on-one be incorporated in the neighborhood administration's apparatus, a collaborative team was set-up (respondent 8 ). This collaborative team was a strong collation of politicians, alderman, developers, civil servants and engaged citizens to ensure that the development of the open source tool was brought to a good end. The team met up four times a year to monitor the developers' progress. At the same time, when the developers needed something, for example a project to pilot test the minimum viable product, the collaborative team could act quickly and ensure synergy between all necessary 'administrative layers' in the neighborhood administration (respondent 1). In addition, expert civil servants could give the developers advice regarding the instrumental requirements for the digital tool for adhering to the ODSF framework and Dutch Personal Data Protection Act. According to respondent 8, the members of the collaborative team were a kind of guardians of the project and ensured that the development of the digital participation tool: "would not end up in the drawer of the alderman but could really be used in the neighborhood administration's machinery."

\subsubsection{Effects}

During the development of the SvW tool, there were little pushbacks or attempts to delegitimize the initiative. According to respondent 1, this was mainly because within the neighborhood council and -administration, there was a supportive group of influential people who went out of their way to bring the development of the open source tool to a good end. Consequently, the developers got enough time (round about 3 years) to fine-tune a tool which could one-on-one be incorporated in the neighborhood administration's apparatus (respondent 8). The user-centered design research and the proto-testing of the Minimum Viable Product ensured that eventually a product was created which considered many types of citizen involvement in the Amsterdam-West neighborhood. Looking back, the developers of the SvW tool, however, had two negative experiences during the development process.

First, respondent 8 points out, "during the proto-typing we realized that 'greening the area' was a hot topic in Amsterdam-West." In this proto-typing phase, the task load of the civil servant responsible for greening issues suddenly increased. Respondent 8 continues, "we initially had not incorporated the more 'low-level' civil servants in our collaborative team." As such, after some harsh words between the developers' team and the civil servant, low-level civil servants were incorporated in the collaborative team to ensure greater support for the SvW initiative among different ranks of civil servants in the neighborhood administration.

A second negative experience happened close to expected launch date of the digital tool. It was just a year before the next neighborhood elections, when the developers heard that the tool had to be launched two months ahead of schedule. In the neighborhood council, some politicians had asked critical questions regarding the progress of the development of the tool. Basically, respondent 1 argues "the politicians wanted to see the result of their 50.000 euro investment - and use it as a start of their political campaigns." The development phase, however, was not yet finished. 
This mainly had to do with the attempts of the developers to program the SvW tool modularly, as a prerequisite to adhere to the ODSF framework (respondent 7). Modular programming entails organizing the complex software behind the tool as a set of distinct components that can be developed independently and then plugged together. According to respondent 7 , "while on paper modular programming seems like a simple idea, my experience is that it takes a lot of time to divide the software up into logical components and develop mechanisms and interfaces to eventually plug the components together." The value of modular programming is that, 'like Lego-cubes', new tools with different functionalities can be made rapidly by the developers of digital participation tools. However, at a certain point in the development of the $\mathrm{SvW}$ tool much time was devoted to the modular programming and less time was dedicated to optimizing the minimum viable product (respondent 7). In consequence, the developers had to launch a final product, after the critical political questions in the neighborhood council, which, in their eyes, was not perfect (respondent 8). Moreover, during the first months after the launch, the developers' team had to make many ad hoc fixes and repairs in the open-source tool to keep it online (respondent 7). Nevertheless, respondent 8 realizes that coping with these 'political dynamics' is also a part of the deal when working in public sector environments.

\subsection{Substantive Uncertainty}

\subsubsection{Management Aims}

So far, we have discussed the development of the digital tool. However, the success of the digital participation tool depends on the substantive use of the instrument. With substantive use, respondent 1 means, "whether topics relevant for the Amsterdam-West's citizens find their way to the neighborhood council's political agenda." In addition, the digital tool must be able to reach a broader audience than organizing participation through so-called 'neighborhood meetings' (respondent 3). Most of the time, these neighborhood meetings only attract twenty to forty 'usual suspects', i.e. citizens who already have regular contact with politicians and civil servants. To this end, the aims of the manager of the SvW project were to foster genuine deliberation on the digital platform and make sure that the online tool has a bigger offline reach than existing democratic participation tools in the neighborhood of Amsterdam-West.

\subsubsection{Solution 1: Nurturing the Matthew Effect}

From the Digital Unit, we got the information that in one year's time, 28963 unique visitors participated on the digital platform. Of this group of visitors 6987 people actively launched a proposal, commented on a proposal, or voted for a proposal. Based on these statistics the neighborhood council concluded that it was worthwhile to make the digital participation process more permanent, as the tool proved to reach a broader audience (respondent 1).

Respondents 9 and 10 are, however, more critical of this reading. According to these civil servants, "the active participants who take the initiative to launch proposals on the digital platform - which can be considered as the most time-consuming task - still are the usual suspects." In their view, there is a certain Matthew effect; implying that digital participation 
has become another vehicle for the usual suspects to communicate their policies and plans. Groups that are not reached by ordinary participation processes are barely reached by digital participation either. Instead the usual suspects manage to link more bystanders (from their own neighborhood networks) to their ideas by asking them through Facebook or offline promotion to support their initiatives. To this end, the neighborhood council cannot paint the picture that, "new audiences are targeted and reached with the digital participation tool", according to respondents 9 and 10.

In consequence, respondent $9 \& 10$ argue, that the neighborhood administration made the deliberate choice to nurture the Matthew effect. This implied that influential 'usual suspects' were facilitated to promote their citizen's ideas in the neighborhood, and thereby, hopefully, generate more discussion on the digital platform. The initiator of the Witte de With street 2030 project, for example, tells that with the help of the municipality, they made a special flyer and handed it out to people living around the street, and they organized a special meeting in the local community center. He continues, "one evening I got a phone call from an old woman arguing that in my plan the tram in front of her house would disappear; the tram was, however, her lifeline to get out of her service flat and visit her family - this information helped us to adjust the plans and gain more support for the proposal by people in the neighborhood." Of course, not all promotors invest the same amount of time and effort in branding their proposals, however, the initiative of WDW2030 has proven that offline marketing increases the likelihood that you get more votes and substantive online discussions, according to respondent 6 .

\subsubsection{Solution 2: Controlling Participation Peaks}

In terms of participation intensity, two proposal peaks can be identified in figure 2 . These peaks were at the start of the digital participation initiative in February 2017 and in November 2017. Respondent 1 explains, "in the beginning, we (i.e. 'the neighborhood council') campaigned through the local broadcasting agency AT5 and we did target marketing on Facebook to ask specific groups of people to submit proposals." In consequence, the neighborhood council received 26 citizens' proposals in the first 3 months. This also entailed, however, quite a lot of extra work for the neighborhood council members and the civil servants. Therefore, the neighborhood administration stopped campaigning for the digital democracy initiative after April 2017. However, at a certain point the number of online proposals decreased. This decrease in the amount of proposals can partly be explained by the fact that politicians and citizens are on holiday in the summer period (respondent 1). In addition, some promotors of proposals realized that their task was not only limited to submitting an idea but also to help with the implementation of the idea. This extra responsibility made some people hesitant to submit a new, or help with another, proposal (respondent 6). 


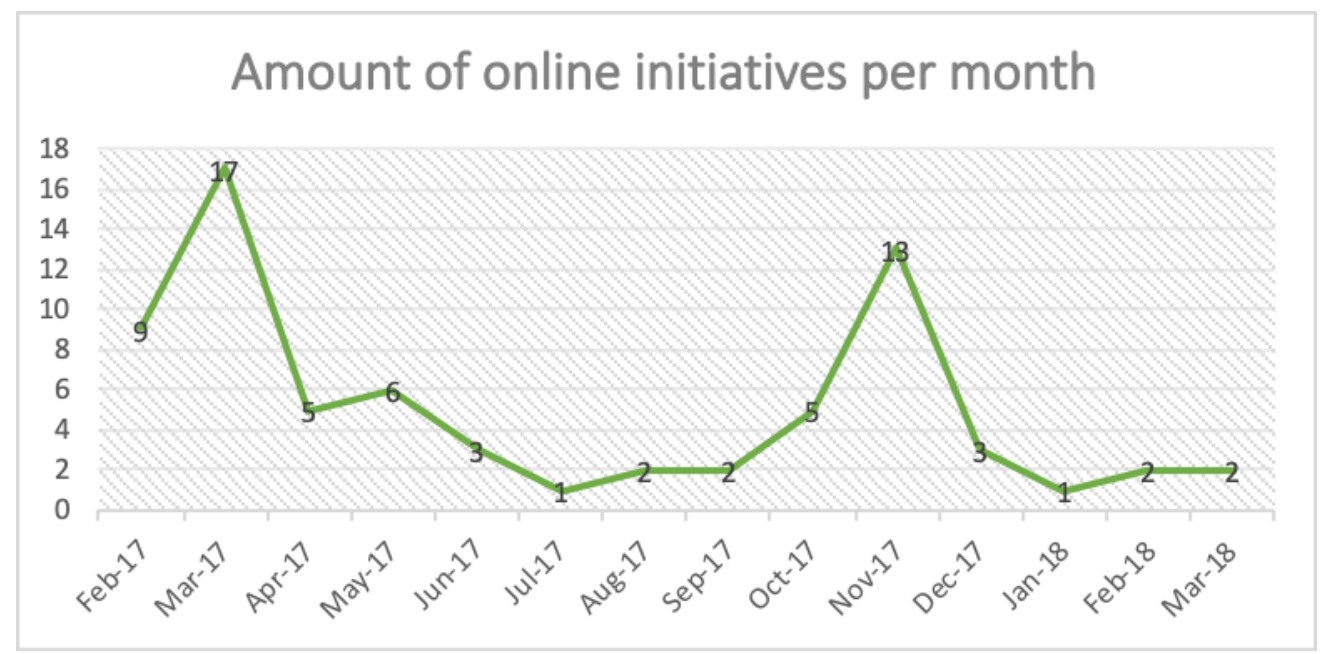

Figure 2. Graphical representation of the amount of initiatives per month

Around October, political parties started campaigning for the upcoming neighborhood elections. This brought back some new energy and political discussions in the neighborhood (respondent 6). Political parties took more opportunities to proliferate their viewpoints by organizing many meetups in the neighborhood. For citizens, this created, at the same time, the opportunity to (strategically) gain more support for their wishes and demands, because, according to respondent 1, "politicians wanted to show that they understood the citizen's needs." In consequence, we observe a rise in the amount of proposals that were submitted on the digital SvW tool in November 2017. Now, on average, 3-4 new ideas are submitted monthly. According to respondent 3, these figures show that the intensity of the digital participation process, in terms of active citizen engagement, depends on whether the neighborhood administration decides to actively control the participation peaks by stopping activities of online promotion and target marketing and whether or not a lot of political activity (e.g. upcoming elections) takes place in the neighborhood.

\subsubsection{Solution 3: Structuring the Platform's Interface and Mediators}

To foster genuine debate on the platform, the manager made two deliberate choices. First, the platform, and more specifically the interface of the platform, was - after some trial and error structured in such a way that arguments in favor and against are placed in two separate columns. According to respondent 8, "this structure makes it harder for arguments to go off-topic, instead encouraging positive points, curbing negativity and avoiding personal attacks." In addition, respondent 8 continues, "the trend of the loudest voices becoming dominant is mitigated with minority and majority opinions getting equal weight in the platform's algorithm, thus thereby facilitating consensus." Secondly, seven neighborhood council members act as moderators on the platform to ensure that positive discussions emerge (respondent 6). These seven council members followed a special course program to learn skills of how to neutrally intervene in online discussions. Within the neighborhood council there is a strict protocol for intervening on the digital platform. The main rule of intervention is when a comment discredits a person, calls for violence, or harms the participation of other 
citizens on the platform. According to respondent 6, "neighborhood council members, however, seldom delete messages."

\subsubsection{Effects}

According to respondent 3, it remains a difficult management task to facilitate dialogue. She argues, the conditions for debate can be optimized, but it remains up to the participants themselves how they behave and interact with one another on the platform. In total, 71 citizen proposals were launched in one-year' time. 25 of the 71 proposals obtained enough 'societal support' in terms of getting more than 100 likes on the digital platform. This equals $35.2 \%$ of the total amount of proposals. On average, each proposal received 7.5 comments. Most of these comments were in favor of the proposal. Nevertheless, each proposal also received negative feedback, which - according to respondent 1 - also helped the politicians to get a better gist of what citizens' attitudes were towards an idea. 13 of the 71 proposals (equals $18.3 \%$ ) received enough political support in the neighborhood council to be executed. This also means that nearly half of the citizens' proposal did not gain enough political support. Overall, more than 7600 votes were given on the digital platform and more than 500 arguments in favor or against. Based on these figures, respondent 3 believes that, "the neighborhood administration has done a good job to reach out to more citizens in the neighborhood and the moderating tweaks on the digital platform helped to stimulate online engagement to citizen proposals."

Table 1 categorizes all 71 proposals into type of issue and uses the metrics of votes and responses to see what sort of issues had a higher propensity to gain societal support (i.e. more than 100 votes in favor) and political support (i.e. be executed after majority approval in the neighborhood council). Three interesting findings come up in the table. First, citizens submit quite a lot of proposals which belong to the policy areas of greening, mobility, spatial planning and waste management. According to respondent 8 , "this is mainly because these are issues which are tangible to people; they see a road, cars or green areas every day when they cycle or drive to work." Secondly, most political throughput can be found in the fields of greening and leisure. Respondent 6 explains, "greening the area is in the current political climate also a priority of many higher-level governments." These higher-level governments provide a lot of funding opportunities for such greening projects. The neighborhood council can thus support these 'green area projects' without spending 'own money' to the citizen initiatives simply by asking higher-level governments for funding. According to respondent 1 , "support for these citizens' initiatives are thus easy and quick wins for political parties in the neighborhood council."

Thirdly, most topics received very few 'negative' responses. This indicates that genuine debate - with good argumentation structures in favor and against the proposal - did not really emerge on the digital platform. As a result, developers of the SvW tool are currently rethinking how more interaction on the SvW tool can be generated though certain incentives and redesign of the platform's interface (respondent $7 \& 8$ ). Suggestions are to simply ask citizens what they think of pre-selected proposals, instead of fostering group dialogue. In fact, in November 2018 an updated digital tool was launched in Amsterdam-West (respondent 6). 
Table 1. Coding of Online SvW Discussions

\begin{tabular}{|c|c|c|c|c|c|c|c|c|}
\hline & $\begin{array}{l}\text { Amount } \\
\text { proposals }\end{array}$ & $\begin{array}{l}\text { Total } \\
\text { votes }\end{array}$ & $\begin{array}{l}\text { Votes in } \\
\text { favor }\end{array}$ & $\begin{array}{l}\text { Votes } \\
\text { against }\end{array}$ & $\begin{array}{l}\text { Total } \\
\text { reactions }\end{array}$ & $\begin{array}{l}\text { Positive } \\
\text { reactions }\end{array}$ & $\begin{array}{l}\text { Negative } \\
\text { reactions }\end{array}$ & $\begin{array}{l}\text { Political } \\
\text { impact }\end{array}$ \\
\hline Culture and Art & 2 & 352 & 342 & 10 & 22 & 22 & 0 & 1 \\
\hline Greening & 8 & 1301 & 1241 & 60 & 87 & 73 & 14 & 3 \\
\hline Housing & 2 & 350 & 347 & 3 & 27 & 26 & 1 & 1 \\
\hline ICT & 4 & 277 & 257 & 20 & 21 & 16 & 5 & 1 \\
\hline Leisure & 4 & 892 & 859 & 33 & 34 & 31 & 3 & 3 \\
\hline Mobility & 16 & 1837 & 1116 & 721 & 170 & 85 & 85 & 1 \\
\hline Safety and security & 2 & 73 & 70 & 3 & 12 & 12 & 0 & 0 \\
\hline Social cohesion & 5 & 267 & 215 & 52 & 15 & 7 & 8 & 1 \\
\hline Spatial planning & 15 & 1108 & 1054 & 54 & 80 & 63 & 15 & 2 \\
\hline Sustainability & 4 & 619 & 611 & 8 & 30 & 30 & 0 & 1 \\
\hline Waste management & 9 & 561 & 535 & 26 & 32 & 29 & 3 & 0 \\
\hline
\end{tabular}

\subsection{Strategic Uncertainty}

\subsubsection{Management Aims}

When citizens and politicians (eventually) agree on implementing a citizen's proposal, it does not immediately imply that the digital democracy initiative functions well. Respondent 1 says, "a digital tool is just an instrument - the value and legitimacy of the digital participation process is eventually also determined by how a citizen's proposal is implemented. On paper there are clear role demarcations between involved political actors, civil servants and citizens for the implementation of citizen's ideas. In practice, however, there were various, 'role conflicts', to quote respondent 1 . She explains, "between actors there seemed to be different expectations both of one's own role, responsibilities and tasks, and the reciprocal roles, responsibilities and tasks of others." Consequently, "there were oftentimes no matching role expectations, causing for delays in projects and frustrations among people who had to work together." One of the big managerial challenges for the SvW coordinator, thus, was to ensure that role-expectation incongruences were tamed. In order to do so, the coordinator used an organizational learning approach to incrementally adapt the neighborhood administration to the altered implementation dynamics of interaction with citizens, politicians and civil servants (respondent 6).

\subsubsection{Solution 1: Learning and Adaptation to Deal With Role-Expectation Incongruences}

From our data, three specific incongruent role expectations can be distilled: citizen-political role incongruence, political-administrative role incongruence, and administrative-citizen role incongruence. Citizen-political role incongruence mostly deals with the difference in expectation regarding where citizens' involvement ends, and political responsibility starts. Respondent 6 points out, "in several cases citizens proposed ideas and expected that after the discussions in the neighborhood council their tasks and involvement were finished; while, politicians tried to hold on to the citizens as much as possible to legitimize their policies and activities." Consequently, some 'citizen participants' felt as if they were 'doing the job of the 
neighborhood administration and alderman' in their spare time without getting paid for the extra activities (respondent 1). According to respondent 1, this is another explanation why after a very promising start of the SvW platform in February, 2017 less proposals were collected in the months June, July and August of that same year (see figure 2). Promotors of the proposals simply did not want to carry the amount of work necessary to implement their ideas.

Political-administrative role incongruence has to do with the impact of the ad hoc decision-making, which follows from the digital democracy process, on the long-term goals of the administrative organization. To elucidate, respondent 1 argues that due to the rise in digital participation, and thereby the increased need to respond quickly to citizens' demands, two 'speeds' have come to co-exist in the administrative organization. One 'political' speed that urges civil servants to ensure as soon as possible that 'accepted' citizen-proposals are executed; and a 'slower' bureaucratic speed that considers the long-term goals of the neighborhood administration. An example of the latter 'speed' are plans to restructure a road intersection. To execute these plans, civil servants must budget (and contract) in advance the possible costs for adapting the sewer system or drawing the new set-up of the intersection. These administrative tasks can collide with a citizen's demand, after a successful digital democracy initiative, to adapt an unsafe pedestrian crossing as quickly as possible. As a result, civil servants sometimes experience that political executives are too involved in micro-managing in the hope to speed up the implementation of a citizen's proposal instead of just keeping overview of the broader administrative processes.

The last, administrative-citizen, role incongruence can be understood as the result of citizens' frustration about 'civil servant's actions who do not know what is happening on the streets' and the need of civil servants to put more expertise in the proposals that are discussed on SvW's digital platform (respondent 6). We interpret this role incongruence as a lack of knowledge sharing in different stages of the policy-making process between citizens and civil servants. After a citizen's proposal gains most votes on the platform and in the neighborhood council, a civil servant must execute the plan in close collaboration with the promotors of the plan (if the promotors are willing to be involved in the execution phase). However, when drafting a proposal, the citizens lack the knowledge about, for example, underground cables or existing land-use plans; making it sometimes impossible for civil servants to fully execute the proposals of the citizens. When civil servants have to give 'the bad news' to the plan promotors they occasionally get the response from citizens that they 'do not know what the citizens of Amsterdam-West want' or 'that the neighborhood administration must work for the people and not vice versa'. After conflict resolution sessions, however, most of the time the collaboration between civil servants and citizens went very smoothly and resulted in a more feasible policy outcome (respondent 6).

In the first year of the experiment, these role incongruences were largely taken for granted. The neighborhood alderman viewed these role incongruences as a part of the learning curve of the experiment (respondent 6). Moreover, respondent 6 argues, "the manager of the SvW project preferred a laissez-faire approach to deal with conflict and issues, as, in the end, it is still people's work." However, when the project, after a positive evaluation of the SvW tool, 
received more structural (i.e. permanent) funding, actors decided to make some repairments to overcome the role expectation incongruences. They realized that for future interactions it was required to have a more fine-grained, day-to-day regulation of the actor network based on precise knowledge of the digital democracy processes. In this way, it was the goal to make the digital democracy process less of an 'island' compared to the rest of the administrative organization (respondent 1). Specifically, three repairments were made:

1. Before a proposal would be put on the agenda of a neighborhood council meeting, a responsible civil servant would write an advisory report regarding the feasibility of the citizen's proposal;

2. After a proposal would obtain enough support on the digital platform and in the neighborhood council, a broad commission of politicians, citizens and civil servants would be established to monitor the progress of the implementation of the proposal. When within the neighborhood administration the implementation would be delayed, this commission had the right to intervene or to straighten things out;

3. Civil servants would receive more training and education to become more acquainted with digital forms of citizen participation and ways to show a more open attitude towards citizens' involvement.

\subsubsection{Effects}

It is still too soon to assess the impact of these repairments (respondent 1). These changes are only recent and there is still room to grow as a neighborhood administration. Currently, the earlier-mentioned WDW2030 project is used as a pilot case to experiment with how to ensure closer links between citizens' input and organizational throughput. The alderman expects a lot from the WDW2030 project because there is a strong coalition of citizens involved in the execution of the process (respondent 6). In the last months, the citizens were invited to discuss with the civil servants and the building company all kinds of possibilities regarding restructuring and greening the street. One visible effect, according to respondent 8 , is that citizens got more understanding of the slower pace in which the bureaucratic apparatus is moving versus the faster short-term citizen's expectation, "that you only have to put a shovel in the ground to renovate the Witte de Withstraat." He explains, "citizens have become more aware of all the organizational- and process coordination that comes along with implementing a new citizen's proposal."

\section{Discussion and Conclusion}

To conclude, research from an applied e-democracy perspective on the management of digital democracy processes has been scarce. Therefore, we examined the management strategies of the manager of the digital democracy 'Stem van West' project in the neighborhood of Amsterdam-West, the Netherlands. Furthermore, we developed a taxonomy of uncertainties managers face in the management of digital democracy processes. We used the taxonomy as a heuristic to cluster what managerial challenges were present in the empirical case, and subsequently, to see what management interventions respectively enhanced or impeded the development, implementation, and execution of the digital democracy project. From our case 
analysis, it became clear that, despite the positive connotations of the word 'digital democracy' and the high expectations policymakers have with regard to the potential of digital democracy tools, in reality, it takes a lot of managerial effort, time, and (incremental) adaptability of the governance- and democratic structure to incorporate digital democracy processes in the bureaucratic machinery of a neighbourhood administration. Management, as such, can help to achieve synergies and foster connections between citizens, politicians and civil servants. At the same time, management can sometimes even be a plain unworkable exercise. Overall, we believe that based on our case results for each type of managerial uncertainty a lesson can be drawn regarding how a manager can contribute to the maturation of a digital democracy project.

The first lesson relates to the aspect of product uncertainty and follows from the way in the digital democracy tool 'Stem van West' was developed. Specifically, it took around three years' time to work towards a full-fledged digital tool which could one-on-one be incorporated in the neighbourhood administration's apparatus. To achieve this, the developers followed a very incremental process in which not only was tested what the different user preferences were of participants of the digital participation process, but also - through proto-testing - how the digital democracy process, as an extra channel of decision-making, would impact the governance processes for the neighbourhood council members and civil servants. Especially, with the development of a Minimum Viable Product, developers consciously added new features to the digital participation tool based on the experiences that followed from feedback from participants and other involved actors. In this sense, the development process was open, transparent and inviting for actors to join and contribute to the product development process.

Hence, on the basis of these case dynamics, we advise neighbourhood administrations, or other levels of government, which are also interested in adding a digital democracy tool to their participation toolbox, to take sufficient time to come up with a product that is ready to tailor usage to the needs and interests of those participating in the digital democracy process. This first lesson has some resonance in the digital government literature. West (2005: 16), for example, argues that the democratic performance of digital participation tools increases if developers critically assess, and thereby take the time to see, whether new features of a digital tool (ranging from simple things such as placing audio or visual materials online to more interactive mechanisms of communication that allow citizens to vote, make comments on proposed ideas, etc.) actually improve the ability of citizens to leave their mark on a decision-making process.

For the aspect of substantive uncertainty the following lesson stands out in the case study: if managers of a digital democracy process do not reach out to influential people in the neighbourhood and promote the possibility to suggest new policies on the open-source tool, deliberation on the digital platform and a bigger offline reach than non-digital participation tools will not occur. In the Amsterdam-West case, the digital participation tool has mostly become another vehicle for the usual suspects, who often already have strong ties with the neighbourhood administration, to communicate their plans and policies. With the online digital tool, they have been able to link more bystanders from their own social networks in 
the neighbourhood to their ideas. Although, creating this accumulation effect for the usual suspects was initially not the goal of the neighbourhood administration, they started facilitating the offline promotion of the ideas of the usual suspects as the number of visitors and participants on the digital tool rapidly increased. In addition, they introduced target marketing to stimulate (other) people to also add ideas to the digital platform's interface. The effects of these interventions were most noticeable just after the intervention took place, as the amount of online initiatives peaked in the two months after the promotional activities of the neighborhood administration up to the level that civil servants requested to stop the Facebook advertisements and target marketing as they drowned in new workload. So, the neighbourhood administration did not really intervene substantively in the online discussions, they mainly tried to optimize the conditions for debate. Their efforts, thus, show that understanding the offline neighbourhood dynamics, and base your promotional activities on these social dynamics, help to stimulate greater online engagement to citizen proposals.

A third important lesson that follows from our case study is that stakeholders of a multi-actor digital democracy project must in the implementation phase discuss and overcome incongruent role expectations to avoid that demanded tasks and activities are not executed due to strict task delineations and entrenched role positions. This lesson stresses the importance of a manager as an 'expectation- and task manager' in digital democracy processes. In our case, we specifically saw, in terms of strategic uncertainty, that stakeholders were foremost busy with what they perceived what their own task were in the digital democracy process. In addition, they were reluctant to take on the 'extra' tasks other stakeholders expected from them. Just like Huxham and Vangen (2005), however, we believe that a real collaborative advantage (in our case: efficient implementation of citizen's proposals) can only be created if stakeholders do not hold on too much to their own task instructions and priorities, but instead also take some risk by seeking for more convergence with their partners' skill, tasks and expectations. Especially, when organizational flexibility is requested with a new 'digital democracy' decision-making channel that is being established next to existing democracy- and governance processes within the neighbourhood administration's apparatus.

Of course, this research also has certain limitations. In the article, we already addressed the small-N problem of a single case study, and thereby the issue of context-dependent generalizations. Additionally, we only studied the management of a digital democracy process which eventually changed the democratic- and governance dynamics of a neighborhood administration, but we did not compare our findings to a case where this was not the case. In consequence, the managerial approaches that we suggest to be most beneficial for digitial participation projects can have a smaller positive impoact than we proclaim. Therefore, we, propose that prospective studies examine the management of the failed development and/or failed execution of digital participation projects. Such an analysis would verify or falsify our research findings. In this way, we believe that the research niche of applied e-democracy can further mature, and thereby enrich the scholarly debates on how management can spur digital participation in the public sector. 


\section{Acknowledgement}

This project has received funding from the H2020 TROPICO project, with project number 726840 .

\section{References}

Chambers, S. (2003). Deliberative Democratic Theory. Annual Review of Political Science, 6(1), 307-326. https://doi.org/10.1146/annurev.polisci.6.121901.085538

Dunne, K. (2008). The value of using local political online forums to reverse political disengagement. $\mathrm{PhD}$-thesis of the University of Surrey.

Flyvbjerg, B. (2011). Case study. This is a chapter. In Denzin, N. K. \& Y.S. Lincoln (Eds). The Sage Handbook of Qualitative Research (pp. 301-316). Thousand Oaks, CA: Sage.

George, A. L., \& Bennett, A. (2005). Case Studies and Theory Development in the Social Sciences. Cambrige, MA: MIT Press.

Huxham, C., \& Vangen, S. (2005). Managing to collaborate: the theory and practice of collaborative advantage. Abingdon, UK: Routledge.

Karlsson, M. (2010). What Does it Take to Make Online Deliberation Happen? A Comparative Analysis of 28 Online Discussion Forums. Paper prepared for the IV International Conference on Online Deliberation in Leeds, UK, 30th of June - 2nd of July 2010.

Klijn, E. H., \& Koppenjan, J. F. M. (2016). Governance Networks in the Public Sector. London, United Kingdom: Routledge.

Koppenjan, J. F. M., \& Klijn, E. H. (2004). Managing Uncertainties in Networks: a network approach to problem solving and decision making. London, United Kingdom: Routledge. https://doi.org/10.4324/9780203643457

Milner, H. (2002). Civic literacy: how informed citizens make democracy work. Hanover, N.H.: University Press of New England.

Muller, G. (2011). Architectural reasoning explained. Retrieved May 31, 2019, from: http://www.gaudisite.nl/ArchitecturalReasoningBook.pdf.

Ostling, A. (2010). ICT in politics: from the peaks of inflated expectations to the void of disillusionment. European Journal of E-practice, 9(1), 1-8.

Peña-López, I. (2011). The disempowering Goverati: e-Aristocrats or the Delusion of e-Democracy. eJournal of eDemocracy and Open Government, 3(1), 1-21. https://doi.org/10.29379/jedem.v3i1.50

Smith, G. (2009). Democratic Innovations: Designing Institutions for Citizen Participation. Cambridge, UK: Cambridge University Press. https://doi.org/10.1017/CBO9780511609848

West, D. M. (2005). Digital Government; technology and public sector performance. 


\section{Macrothink}

Princeton, NY: Princeton University Press.

\section{Copyright Disclaimer}

Copyright for this article is retained by the author(s), with first publication rights granted to the journal.

This is an open-access article distributed under the terms and conditions of the Creative Commons Attribution license (http://creativecommons.org/licenses/by/4.0/). 